\title{
Development of approaches to the diagnosis of cattle leukemia in the system of antiepizootic measures in the Belgorod Region
}

\author{
Anatoly Kovalenko ${ }^{1 *}$, Irina Donnik $^{2}$, Andrey Dorofeev ${ }^{1}$, Svetlana Belyaeva $^{1}$, Nazar $_{\text {Yavnikov }}{ }^{1}$, Victoria Oskolskaya ${ }^{1}$ \\ Danila Karaychentsev ${ }^{3}$, and Maxim Petropavlovskiy ${ }^{4}$ \\ ${ }^{1}$ Belgorod State Agrarian University named after V. Ya. Gorin, vil. Mayskiy, Russia \\ ${ }^{2}$ Russian Academy of Sciences, Moscow, Russia \\ ${ }^{3}$ Veterinary Department of the Belgorod region, Belgorod, Russia \\ ${ }^{4}$ Ural Federal Agrarian Research Center of the Ural Branch of the Russian Academy of Sciences, Yekaterinburg, Russia
}

\begin{abstract}
The aim of the research is the use of serological and molecular genetic methods for detecting virus-infected cattle leukemia, as well as determining the significance of PCR in identifying BLV infected calves in the system of antiepizootic health measures. The developed technique for early diagnosis of leukemia in cattle made it possible to accelerate the process of recovery of disadvantaged farms in the Belgorod region by increasing the frequency of studies from 6 months to 2-3 months and an increase in the sensitivity of the agar-gel immunodiffusion test. This, in turn, leads to an increase in the sensitivity of the agar-gel immunodiffusion test and makes it possible to detect, on average, from $8.8 \%$ to $20.25 \%$ more animals infected with the leukemia virus compared to the standard reaction of the agar-gel immunodiffusion test. The additional use of molecular genetic tests for the detection of proviral DNA of the leukemia virus makes it possible to identify at the early stages of the development of the leukemia process, in calves from 15 days of age, the genomic material of bovine leukemia virus, which will also allow in a shorter time to carry out a qualitative improvement of young cattle in dysfunctional farms.
\end{abstract}

\section{Introduction}

Viral infectious diseases of animals continue to occupy a dominant position in the system of antiepizootic measures carried out at livestock agricultural enterprises of the Belgorod region. One of the most pressing diseases in this case is cattle leukemia (EBL) both in the Belgorod region and in most countries of the world, causing a high level of infection in livestock and the associated economic costs of antiepizootic measures. A rather late detection of infection in animals, despite the use of modern diagnostic tests, contributes to the wide spread of leukemia in cattle $[1,2]$. Modern requirements for recovery from bovine leukemia are in need of early detection of virus-infected animals in the early stages of development of the incubation period. Ways to solve this problem require the development of new possibilities in the diagnosis and prevention of viral infectious diseases of animals in the system of antiepizootic measures. Bovine leukemia (EBL), caused by B-lymphotropic leukemia virus (BLV), belongs to the RNA-containing viruses of the Retroviridae family, the genus Deltaretrovirus, is a slowrunning chronic infectious disease of a tumor nature $[3,4$, 5]. Leukemia is still one of the most economically significant diseases, causing significant damage to the development of dairy and beef cattle breeding, and also has a potential danger to humans [6-15]. The efficiency of detecting sick animals at earlier stages of development of the incubation period with slowly progressing infections is the key to the formation of stable well-being in cattle leukemia. The process of effective recovery of cattle from leukemia was significantly accelerated due to the use of developed serological diagnostic test systems that facilitate the rapid identification of infected individuals during the implementation of health-improving and preventive measures [16]. The basic serological test for detecting infected cattle leukemia virus is the reaction of the agar-gel immunodiffusion test followed by the use of a hematological test [17]. In addition, in recent years, the method of molecular genetic analysis (polymerase-chain reaction) has been increasingly used to diagnose bovine leukemia. The high specificity of this method is achieved due to the detection of a fragment of the leukemia virus proviral DNA. The specificity is determined by the nucleotide sequence of the primers, which eliminates the possibility of false results. The polymerase-chain reaction method has high sensitivity, making it possible to detect single fragments of viral nucleic acids [18]. The difficult epizootic situation of bovine leukemia in the Russian Federation, including in the dairy enterprises of the Belgorod region, served as the beginning of research on the early detection of infected animals in dysfunctional farms in order to increase the success of the anti-leukemic health measures.

The aim of the research is the use of serological and molecular genetic methods for detecting virus-infected

* Corresponding author: mycobacteria@rambler.ru 
cattle leukemia, as well as determining the significance of the polymerase chain reaction in identifying BLV infected calves in the system of antiepizootic health measures in the Belgorod region. The subject of the research is epizootic screening for bovine leukemia in the Belgorod region and the development of approaches to early diagnosis of bovine leukemia. The object of the study is dairy cattle, animals infected and sick with leukemia.

\section{Materials and methods}

The research was carried out on the basis of the Belgorod State Agrarian University (testing laboratory, laboratory for the study of infectious and invasive diseases and approbation of veterinary drugs); Shebekinskaya interdistrict veterinary laboratory; using the data of the Belgorod Veterinary Directorate on the epizootic state in the dairy farms of the Belgorod region with leukemia LLC MMF Nezhegol and JSC Orlik p. Voskresenovka, Chernyansky District; CJSC "Voskhod" and LLC "Pobeda" of Shebekinsky district. Research methods epizootological, serological (of the agar-gel immunodiffusion test), hematological and molecular biological (polymerase chain reaction) research methods. The material for the research was epizootological data on the prevalence of bovine leukemia, as well as blood serum and stabilized blood from cattle in dairy farms of prosperous and dysfunctional farms for bovine leukemia. Blood samples were taken with disposable instruments into sterile tubes from the tail vein to obtain blood serum for studies in the agar-gel immunodiffusion test, as well as stabilized blood for studies by the hematological method and polymerase chain reaction. The studies were carried out according to the approved methods: methodology for epizootological examination of cattle (Order of the Ministry of Agriculture and Food of the Russian Federation of 11.05.1999 N 359 "On the approval of the rules for the prevention and control of leukemia in cattle", registered in the Ministry of Justice of the Russian Federation on 04.06.1999 N 1799); - methodology for conducting hematological, serological studies and molecular biological methods (Guidelines for the diagnosis of bovine leukemia, approved by the head of the Veterinary Department of the Ministry of Agriculture of the Russian Federation M.V. Kravchuk on 08/23/2000, N 13-7-2 / 2130) ; - hematological studies of the blood of animals were carried out on an automatic hematological analyzer URIT-3020 (China) according to the instructions for working with this device. Visualization of hematological parameters on a glass slide after Leishman staining was carried out on a Labor microscope, $60 \mathrm{X} / 0.75$ with a built-in camera. Counting leukocytes in the Goryaev chamber according to the method of I.P. Kondrakhin - Molecular genetic studies (polymerasechain reaction) - used the test system "Leukemia" according to the instructions for its use, approved by the head of the Rosselkhoznadzor dated 19.05. 2009 [18]. Statistical processing of the data was carried out by the methods of variation statistics in the form of calculating the arithmetic mean, standard deviation and coefficients of variation using the Microsoft Office Excel 2007 software.

\section{Results and discussion}

The epizootic situation in bovine leukemia has remained unchanged in the Russian Federation over the past few years. Thus, the number of cattle most infected with BLV is in the Central Federal District and is more than $41 \%$. (Fig. 1).

Federation conducted retrospective and prospective monitoring epizootic studies to study the epizootic situation of BLV infection in dairy farms in the Belgorod region showed that prior to the start of the rehabilitation plan for cattle leukemia, the situation remained tense in the region. It should be noted that in most farms belonging to large holdings, the level of infection with leukemia in cattle is significantly lower in comparison with dairy farms containing aboriginal cattle for a long period of lactation

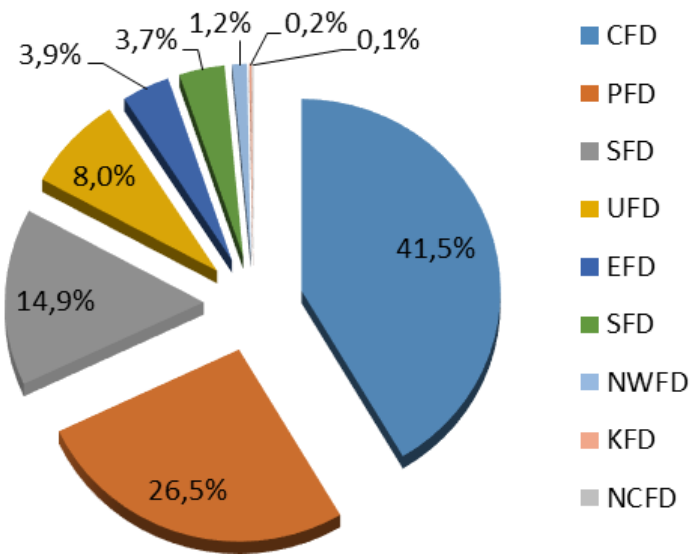

Fig.1. Study of the epizootic situation of cattle leukemia in the Russian.

This is primarily due to the fact that in dairy holdings, animals are exploited a small number of lactations, on average from 2 to 4 , and since this infection is slow, it is possible to detect the presence of anti-leukemia antibodies in such animals using the agar-gel immunodiffusion reaction by 2-3 lactation. At the beginning of the year, in the dairy farms of the Belgorod region, the farms of the Shebekinsky and Chernyansky districts of the region were mostly unfavorable for leukemia in cattle, in which there were a significant number of the agar-gel immunodiffusion (+) animals - up to $85 \%$. The developed approach to the diagnosis of bovine leukemia in the system of antiepizootic measures in the Belgorod region, in dysfunctional farms, is based on a two-fold reduction in the frequency of serological studies and an increase in the desired serum antiviral antibodies in the test samples during immunodiffusion reactions.

So, at the beginning of the year in the Belgorod region, there were only four farms unfavorable for leukemia in cattle - LLC MMF Nezhegol (dairy farm No. 1), JSC Orlik (dairy farm No. 2), CJSC Voskhod (dairy farm No. 3 ) and LLC "Pobeda" (dairy farm No. 4) of the Belgorod region - with an infection rate from 31.7 to $84.1 \%$, and at the end of the year these indicators decreased, respectively, from 11.5 to $80.2 \%$ as a result of the developed approach to diagnostics of cattle leukemia in the system of antiepizootic measures in the Belgorod region (Fig. 2). 
At the beginning of 2020 , in the Belgorod region, dairy farm Nezhegol LLC and Orlik AO s. Voskresenovka of Chernyansky district (dairy farm No. 1 and No. 2); Voskhod CJSC and Pobeda LLC of Shebekinsky District (dairy farm No. 3 and No. 4), and at the end of the reporting period of 2020, it was possible, using the approaches of early diagnosis of bovine leukemia, improving the farm health improvement system, to fully improve the livestock of Orlik JSC (dairy farm No. 2). In general, in the Belgorod region as of January 2020, taking into account the unfavorable conditions of leukemia in cattle among the four abovementioned farms with a livestock of 6605 heads, 3343 heads were identified as react in the agar-gel immunodiffusion test, which was $50.6 \%$. At the same time, hematologically sick individuals were identified 219 heads (6.55\%) (Fig. 3). At the end of 2020, the use of the developed technique for early diagnosis of bovine leukemia in order to improve the health improvement system made it possible to increase the detection rate of infected livestock in the agar-gel immunodiffusion test from 1668 to 1741 heads, which was $6.35 \%$ more than at the beginning of the study period. As for the isolation of animals with hematological leukemia in cattle, at the end of the year their number was only 22 heads, which in percentage terms was $1.26 \%$. This is 5.2 times less than at the beginning of the year.

To test the improved methodology for setting up the immunodiffusion reaction in agar-gel, 1251 samples of cattle blood serum were taken from a dysfunctional leukemia farm - Pobeda LLC. In the experimental part of the research, various centrifugation methods and temperature regimes were used for these samples of animal blood serum in order to identify the maximum number of additional of the agar-gel immunodiffusion $(+)$ of bovine heads that previously gave negative immune diffusion reactions in the standard setting of the agar-gel immunodiffusion test. As a result of the studies, a direct relationship was established between the concentration of the desired antibodies in the tested sera (high-speed centrifugation) and the absolute binding of antibodies to antigens under conditions of the reaction that are more physiologically close to in vivo $\left(37^{\circ} \mathrm{C}\right)$. This leads to an increase in the sensitivity of the agar-gel immunodiffusion test, and also makes it possible to detect, on average, $20.25 \%$ more animals infected with the leukemia virus compared with the standard agar-gel immunodiffusion test. The use of the proposed method for the diagnosis of leukemia in cattle makes it possible to identify animals infected with leukemia at earlier stages, which are in the initial period of the production of antileukemic antibodies, which makes it possible to reduce the time they spend in the herd, and this ultimately helps to accelerate the implementation of health-improving measures without requiring significant material and time costs. In the complex of diagnostic studies, as an additional research method, a polymerase chain reaction was used using the Leukemia test system on the livestock of Pobeda LLC calves obtained from the agar-gel immunodiffusion of $(+)$ animals. In a pilot study in January 2020, 22 samples of clinical material from young animals up to 2 months and in the maternity ward - calves up to 3 weeks - 3 heads tested positive for the presence of bovine leukemia virus.

Further, a study was carried out of the total number of calves from 15 days to 6 months, obtained from the IDR $(+)$ cows (table I). As a result of the studies, in January, from 114 calves (blood samples) in 16 samples, the presence of bovine leukemia virus was detected, which amounted to $11.11 \%$. These data provided the rationale that in subsequent studies conducted in May-June, this test was also used on calves in order to prevent the spread of leukemia through infected young animals. Since these individuals are sources of the causative agent of infection and, being in a common herd with other calves, they infect the rest of the livestock with the leukemia virus. In order to avoid and to exclude the presence of this mechanism of transmission of leukemic infection, subsequent studies using polymerase chain reaction were carried out every three to four months. Studies carried out in May of blood samples from 50 head of calves, from 15 days to 3 months, revealed the presence of bovine leukemia virus in 14 samples, i.e., in $28 \%$ of samples received from this livestock. Later, in June, already in the study of calves from 15 days to 1.5 months, only 2 samples were identified out of 36 blood samples, in which the bovine leukemia virus was present, which was $5.5 \%$ of the total number of animals studied. In general, during the study period, the presence of leukemia virus was detected in 32 calves up to 6 months of the total number of 230 calves obtained from the reaction of the agar-gel immunodiffusion $(+)$ cows, which amounted to $13.9 \%$ (table I). All calves in which the proviral DNA of the leukemia virus was detected in the blood were removed from the general herd and fed in a separate room for removal after gaining the appropriate weight from the farm.

Thus, molecular genetic studies using the polymerase chain reaction of the Leukemia test system allowed identifying 32 infected calves, which amounted to $13.91 \%$. In the system of antiepizootic measures to accelerate the recovery of dysfunctional farms, we proposed to reduce the frequency of serological studies from 6 to 3 months. Since a six-month period of research can contribute to reinfection, the agar-gel immunodiffusion (-) of animals with infected individuals in the early stages of the development of the leukemia process, in which antibodies to bovine leukemia virus have not previously been detected in the agar-gel immunodiffusion test and which had a low antiviral antibody index. The developed approach to the diagnosis of leukemia in cattle during the implementation of healthimproving measures made it possible to fully recover from leukemic infection the number of cattle dairy farm JSC “Orlik" p. Voskresenovka, Chernyansky District (dairy farm No. 2), and in the other two previously unsuccessful farms for leukemia: CJSC Voskhod and OO Pobeda (dairy farm No. 3 and No. 4), in Shebekinsky District, Belgorod Region, reduce the infection rate from $56.4 \%$ and $84.1 \%$ to $41.4 \%$ and $11.5 \%$, respectively (table II).

Analyzing the data in table II, it should be noted that the most successful anti-leukemic measures using the developed approach to diagnostics were at CJSC "Voskhod" (dairy farm No. 3). In this farm, at the 
beginning of the year, before the use of early diagnosis, there were $56.4 \%$ of infected individuals, and at the end of the study period, $41.4 \%$, i.e., the number of infected animals decreased by $15 \%$, and the excretion rate of hematologically sick animals decreased from $12.3 \%$ to $1.9 \%$, i.e., 6.5 times (table II, Fig. 6).

In OOO "Pobeda" (dairy farm No. 4), the rate of leukemia infection in cattle decreased from $84.1 \%$ to $11.5 \%$, i.e. by $72.6 \%$, however, the number of hematologically sick animals increased intensively from $3.5 \%$ to $16.4 \%$ (table I, Fig. 7 ). At OOO Nezhegol (dairy farm No. 1), the process of more active detection of leukemia-infected and hematologically sick animals is observed through the use of early diagnosis. This is manifested by an increase in the number of infected and hematologically sick animals by $17 \%$ and $3.5 \%$, respectively. In our opinion, this is due to the presence of a larger number of animals, in comparison with previous farms, which are in the latent stage of the leukemia process with a low antibody index, which in turn affects the results of the agar-gel immunodiffusion test (table I, Fig. 4).
Thus, it is necessary to note the application of the developed approaches to the early diagnosis of bovine leukemia when carrying out health-improving antiepizootic measures made it possible to completely recover from leukemic infection the number of cattle in the dysfunctional dairy farm Orlik JSC (dairy farm No. 2) (table I, Fig. 5), and in the other two previously unsuccessful farms for leukemia: CJSC "Voskhod" and OO "Pobeda" to reduce the level of infection, respectively, from $56.4 \%, 84.1$ to $41.4 \%, 11.5 \%$. The effectiveness of the used early diagnosis of bovine leukemia when carrying out antiepizootic health measures in these two dysfunctional farms is evidenced by the data on 2 and 3.6 times decrease in the infection rate of susceptible livestock of animals, respectively, in dairy farm No. 3 and dairy farm No. 4 (Fig. 6-7).

In general, on all dysfunctional farms, due to the impeccable implementation of the plan for the implementation of the program to improve the recovery of the Belgorod region from cattle leukemia, it was possible to reduce the level of infection of the livestock of BLV animals by half (Fig. 8).

Table 1. Results of the study of blood samples from calves of LLC "POBEDA" in the polymerase chain reaction using the "leukemia" test system

\begin{tabular}{|c|c|c|c|c|c|}
\hline № & $\begin{array}{c}\text { Total inspected } \\
\text { calves (n) }\end{array}$ & Age of animals & $\begin{array}{c}\text { Number of positive } \\
\text { samples in PCR }\end{array}$ & $\begin{array}{c}\% \text { to the total number of } \\
\text { tested samples in the PCR }\end{array}$ & Note \\
\hline \multicolumn{7}{|c|}{ January } \\
\hline 1 & 144 & 15 days -6 months & 16 & 11,11 & $\begin{array}{c}\text { Number of heifers for } \\
\text { the study period }\end{array}$ \\
\hline 2 & 50 & 15 days -3 months & 14 & 28,0 & $\begin{array}{c}\text { Number of heifers born } \\
\text { during the study period }\end{array}$ \\
\hline \multicolumn{7}{|c|}{} & June & 5,55 & $\begin{array}{c}\text { Calves from (+) IDR } \\
\text { cows }\end{array}$ \\
\hline
\end{tabular}

Table 2. Dynamics of changes in the level of infection and the number of hematologically sick animals in farms with poor leukemia in cattle on the territory of the Belgorod region for 2020

\begin{tabular}{|c|c|c|c|c|c|}
\hline № & Farm name & $\begin{array}{c}\text { Total livestock, } \\
\text { heads }\end{array}$ & $\begin{array}{l}\text { Infection rate of } \\
\text { animals, } \%\end{array}$ & $\begin{array}{l}\text { Number of the + IDR } \\
\text { animals, heads }\end{array}$ & $\begin{array}{l}\text { Number of revealed } \\
\text { hematologically sick } \\
\text { animals, heads / \% }\end{array}$ \\
\hline \multirow{4}{*}{1.} & \multicolumn{5}{|c|}{ Before using early diagnosis } \\
\hline & dairy farm №1 & 1105 & 67,7 & 748 & $59 / 7,9$ \\
\hline & \multicolumn{5}{|c|}{ After a year of using early diagnosis } \\
\hline & dairy farm №1 & 1090 & 80,2 & 874 & $100 / 11,4$ \\
\hline \multirow{4}{*}{2.} & \multicolumn{5}{|c|}{ Before using early diagnosis } \\
\hline & dairy farm №2 & 3526 & 31,7 & 1118 & $75 / 6,7$ \\
\hline & \multicolumn{5}{|c|}{ After a year of using early diagnosis } \\
\hline & dairy farm №2 & 572 & 0 & 0 & 0 \\
\hline \multirow{4}{*}{3.} & \multicolumn{5}{|c|}{ Before using early diagnosis } \\
\hline & dairy farm №3 & 663 & 56,4 & 374 & $46 / 12,3$ \\
\hline & \multicolumn{5}{|c|}{ After a year of using early diagnosis } \\
\hline & dairy farm №3 & 1637 & 41,4 & 678 & $13 / 1,9$ \\
\hline \multirow{5}{*}{4.} & \multicolumn{5}{|c|}{ Before using early diagnosis } \\
\hline & dairy farm №4 & 1311 & 84,1 & 1103 & $39 / 3,54$ \\
\hline & \multicolumn{5}{|c|}{ After a year of using early diagnosis } \\
\hline & dairy farm №4 & 1009 & 11,5 & 116 & $19 / 16,4$ \\
\hline & TOTAL & 10913 & $59,98 / 33,28$ & $835,75 / 417,0$ & $54,75 / 33,0 ; 7,61 / 7,43$ \\
\hline
\end{tabular}




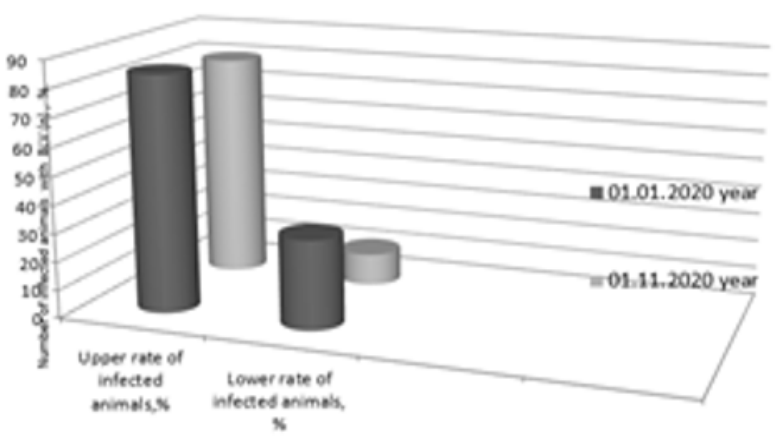

Fig.2. Dynamics of the level of infection with leukemia virus in the number of cattle in stationary leukemiadysfunctional farms of the Belgorod region.

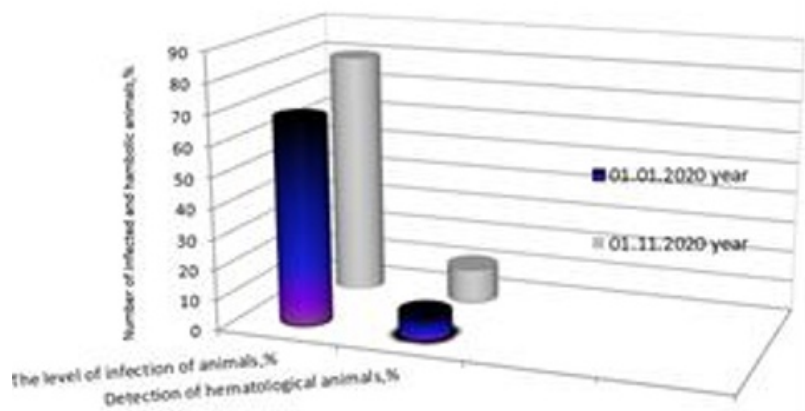

Fig.4. The dynamics of changes in the level of infection and the number of hematologically sick animals in a farm with leukemia in cattle on the territory of the Belgorod region in 2020 (dairy farm No. 1).

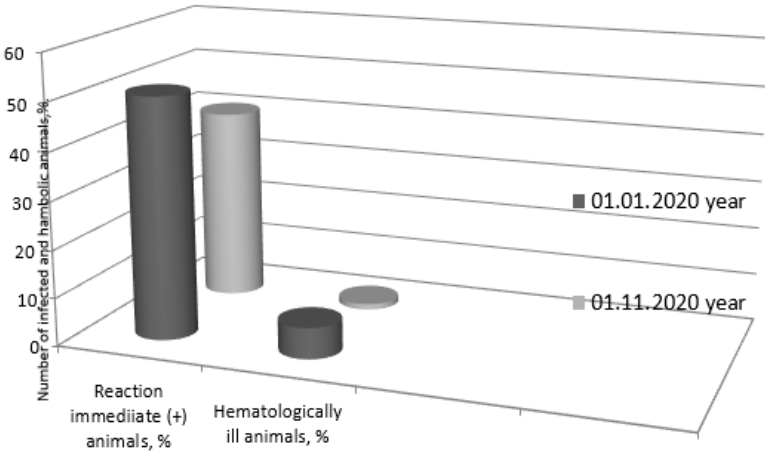

Fig.3. The results of the use of the method of early diagnosis of leukemia in cattle in the recovery of leukemia-dysfunctional farms in the Belgorod region.

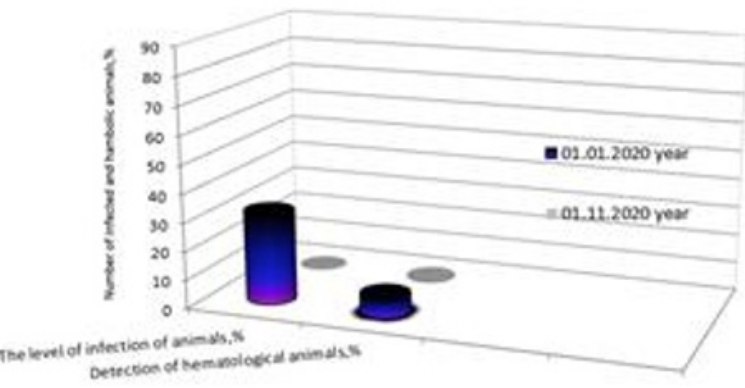

Fig.5. The dynamics of changes in the level of infection and the number of hematologically sick animals in a farm with leukemia in cattle on the territory of the Belgorod region in 2020 (dairy farm No. 2)

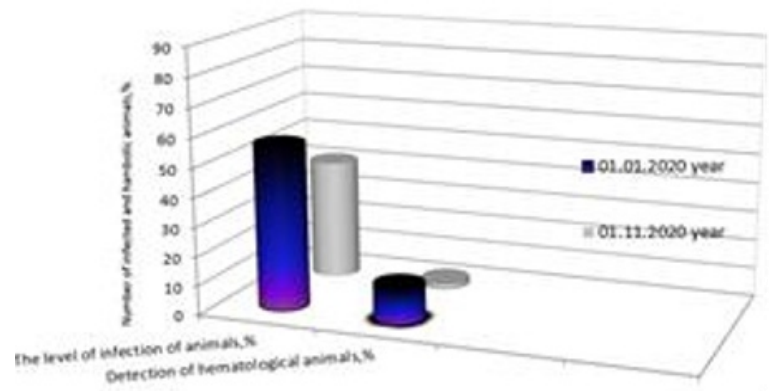

Fig. 6. The dynamics of changes in the level of infection and the number of hematologically sick animals in a farm with leukemia in cattle on the territory of the Belgorod region in 2020 (dairy farm No. 3).

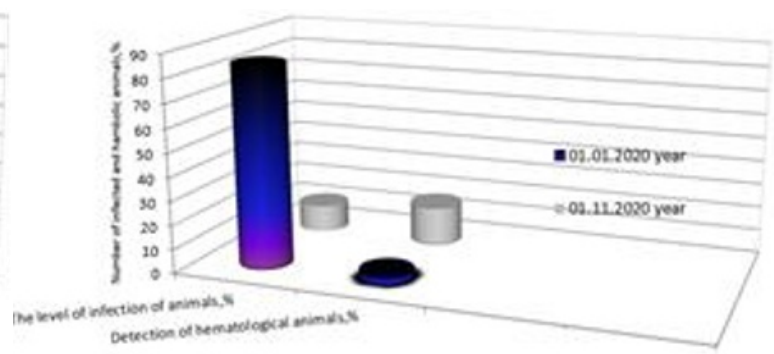

Fig. 7. The dynamics of changes in the level of infection and the number of hematologically sick animals in a farm with leukemia in cattle on the territory of the Belgorod region in 2020 (dairy farm No. 4).

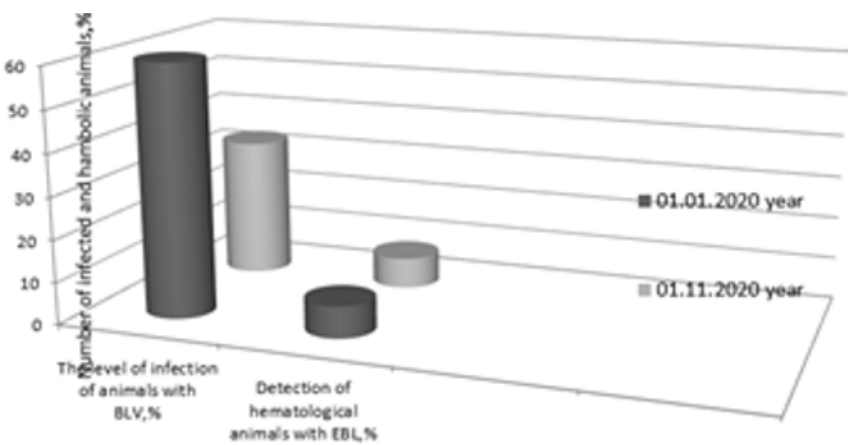

Fig. 8. Dynamics of changes in the level of infection and detection of hematopoietic patients after the use of early diagnosis of leukemia in cattle during the implementation of recreational activities in dysfunctional farms in the Belgorod 


\section{Conclusion}

As a result of monitoring, retrospective and prospective epizootic studies, as well as serological, hematological and molecular genetic studies in conjunction with the state veterinary service of the Belgorod region, it was possible to reduce the level of leukemia infection of the livestock population by half in dairy farms (dairy farm No. 1, No. 2 , No. 3 and No. 4), thanks to strict adherence and implementation of the plan for the implementation of the program for the recovery of the Belgorod region from bovine leukemia. The developed technique for early diagnosis of leukemia in cattle made it possible to accelerate the process of recovery of disadvantaged farms in the Belgorod region by increasing the frequency of studies from 6 months to 2-3 months and an increase in the sensitivity of the agar-gel immunodiffusion reaction, which was accompanied by an intensive decrease in the detection rate of hematologically sick animals 5.2 times and an increase in the number of infected individuals by $6.35 \%$.

The use of early diagnosis of leukemia in cattle during the implementation of health-improving measures has made it possible to fully recover from leukemic infection the number of cattle in the dairy farm JSC "Orlik" s. Voskresenovka, Chernyansky District (dairy farm No. 2), and in the other two previously unsuccessful farms for leukemia: Voskhod CJSC and Pobeda OO (dairy farm No. 3 and No. 4) of Shebekinsky District, Belgorod Region, reduce the infection rate from $56.4 \%$, and $84.1 \%$ to $41.4 \%$, and $11.5 \%$, respectively. When practicing the step-by-step detection of animals with leukemia using the developed approach to the diagnosis of cattle leukemia in the system of antiepizootic measures to enhance the health improvement system in a separate farm, OOO Pobeda, a new approach to staging the reaction of the agar-gel immunodiffusion was developed. It has been proved that the proposed method of improved the agar-gel immunodiffusion test in diagnostics of bovine leukemia is based on establishing a direct relationship between the concentration of the desired antibodies in the tested serum and the absolute binding of antibodies to antigens under more physiologically close to in vivo reaction conditions This, in turn, leads to an increase in the sensitivity of the agar-gel immunodiffusion test and makes it possible to detect, on average, from $8.8 \%$ to $20.25 \%$ more animals infected with the leukemia virus compared to the standard of agar-gel immunodiffusion test. The use of the proposed method for diagnosing leukemia in cattle makes it possible to identify animals infected with leukemia at earlier stages of the development of the leukemia process, which are in the initial period of the production of antileukemic antibodies, which makes it possible to reduce the time they spend in the herd, and this ultimately helps to accelerate the implementation of health-improving anti-leukemic measures without requiring significant material and time costs. At the same time, the additional use of molecular genetic tests for the detection of proviral DNA of the leukemia virus makes it possible to detect the genomic material of bovine leukemia virus at the early stages of the development of the leukemia process in calves from the age of 15 cattle in dysfunctional farms.

\section{References}

1. M.I. Gulyukin, O.V. Kapustina, I.Yu. Ezdakova, S.V. Valtsiferova, T.V. Stepanova, M. Anoyatbekov, Problems of Virology, 64, 173-177 (2019).

2. A.De Brogniez, A.B. Bouzar, J.R. Jacques [et al.], J. Virology, 89, 8945-8956 (2015).

3. M.I. Gulyukin, N.G. Kozyreva, L.A. Ivanova, T.V. Stepanova, A.I. Klimenko, A.V. Kovalenko, Y.D. Drobin, V.N. Vasilenko, Problems of Virology, 60, 32-37 (2015).

4. A.F. Valikhov, Moloch.prom-st, 9, 74-77 (2018).

5. I.M. Donnik, I.A. Shkuratova, A.T. Tatarchuk [et al.], Regulatory issues in veterinary medicine, 2, 4246, 2015.

6. T.V. Stepanova, Russian J. Agricultural and SocioEconomic Sciences (RJOAS). 8, 49-56 (2016).

7. S.V. Timoshina, O.B. Badeeva, Veterinary medicine and feeding, 4, 6-7 (2012).

8. V.A. Mishchenko, O.N. Petrova, A.K. Karaulov, A.V. Mishchenko, The problem of leukemia in cattle (Vladimir: FSBI ARRIAH, 2018).

9. V.V. Khramtsov, N.G.Dvoeglazov, R.S. Khafizova, Innovations and food security, 2, 61-70 (2014).

10. G.M. Sviridenko, Dairy industry, 8, 13-16 (2017).

11. M.C. Frie, K.R. Sporer, J.C. Wallace, R.K. Maes, L.M. Sordillo, P.C. Bartlett [et al.], Vet. Immunol. Immunopathol, 182, 125-135 (2016).

12. S. Suzuki, S. Konnai, T. Okagawa, R. Ikebuchi, A. Nishimori, J. Koharaetal, Vet. Immunol. Immunopathol, 163, 115-124 (2015).

13. H. Murakami, H. Todaka, J. Uchiyama, R. Sato, K. Sogawa, M. Sakaguchiet [et al.], Virology, 537, 4552 (2019).

14. The effect of the drug "Leukozav" on the cellular component of immunity in rats: EESJ electronic journal: [site]. URL: https://eesajournal.com/2017/03/14/vliyanie-preparatalejkozav-na-kletochnoe-zvo

15. I.Yu. Ezdakova, O.V. Kapustina, M.I. Gulyukin, T.V. Stepanova, Problems of Virology, 65, pp. 3540 (2020).

16. I.M. Donnik [et al.], (Yekaterinburg: Scientific advice, THEM. IRA UTK LLC, 2011).

17. I.M. Donnik, G.A. Jailidi, S.V. Tikhonov, Veterinary of the Kuban, 5, 15-19 (2013).

18. Instructions for the use of the test system "leukemia" for the detection of leukemia virus in cattle (cattle) by the polymerase chain reaction, approved May 19, 2009. [Electronic access]. 